\title{
Heart and systemic effects of statin pretreatment in a rat model of abdominal sepsis. Assessment by Te $^{99 m}$-sestamibi biodistribition ${ }^{1}$
}

\author{
Robson Macedo ${ }^{\mathrm{I}}$, Som Mehrbod Javadi ${ }^{\mathrm{II}}$, Takahiro Higuchi' ${ }^{\mathrm{II}}$, Marília Daniela Ferreira de Carvalho ${ }^{\mathrm{IV}}$, Vanessa de Fátima Lima \\ Paiva Medeiros ${ }^{\text {IV }}$, Ítalo Medeiros Azevedov, Francisco Pignataro Lima ${ }^{\mathrm{VI}}$, Aldo Cunha Medeiros ${ }^{\mathrm{VII}}$
}

DOI: http://dx.doi.org/10.1590/S0102-865020150060000003

IFellow PhD degree, Postgraduate Program in Health Sciences, Federal University of Rio Grande do Norte (UFRN), Natal-RN, Brazil. Conception, design, intellectual and scientific content of the study; acquisition, interpretation and analysis of data; manuscript writing.

${ }^{I I} \mathrm{MD}$, Division of Nuclear Medicine, Department of Radiology, Johns Hopkins University, Baltimore, USA. Interpretation and analysis of data, critical revision.

IIIMD, Department of Nuclear Medicine, Wuerzburg University, Wuerzburg, Germany. Interpretation and analysis of data; critical revision.

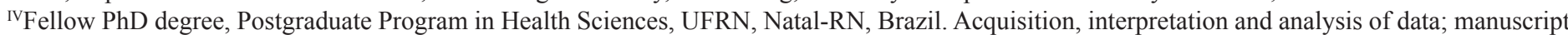
writing.

${ }^{\mathrm{v}}$ Master, Statistician, Department of Surgery, UFRN, Natal-RN, Brazil. Acquisition, interpretation and analysis of data; manuscript writing.

${ }^{V I}$ Associate Professor, Department of Patology, UFRN, Natal-RN, Brazil. Acquisition, interpretation and analysis of data; critical revision.

VIIPhD, Full Professor, Department of Surgery, UFRN, Natal-RN, Brazil. Design and coordination of the study, interpretation and analysis of data, draft the manuscript, critical revision.

\section{ABSTRACT}

PURPOSE: To evaluate the heart and the Tc-99m-sestamibi biodistribution after statin pretreatment in a rat model of abdominal sepsis. METHODS: Twenty-four Wistar rats were randomly distributed into four groups ( $\mathrm{n}=6$ per group): 1 ) sepsis with simvastatin treatment, 2) sepsis with vehicle, 3) sham control with simvastatin and 4) sham control with vehicle. 24 hours after cecal ligation and puncture rats received $1.0 \mathrm{MBq}$ of $\mathrm{Tc}-99 \mathrm{~m}$-sestamibi i.v. $30 \mathrm{~min}$ after, animals were euthanized for ex-vivo tissue counting and myocardium histological analysis.

RESULTS: Myocardial histologic alterations were not detected 24 hours post-sepsis. There was significantly increased cardiac Tc-99msestamibi activity in the sepsis group with simvastatin treatment $(1.9 \pm 0.3 \% \mathrm{ID} / \mathrm{g}, \mathrm{p}<0.001)$ in comparison to the sepsis group $+\mathrm{vehicle}$ $(1.0 \pm 0.2 \% \mathrm{ID} / \mathrm{g})$, control sham group + simvastatin $(1.2 \pm 0.3 \% \mathrm{ID} / \mathrm{g})$ and control sham group $(1.3 \pm 0.2 \% \mathrm{ID} / \mathrm{g})$. Significant Tc-99msestamibi activity in liver, kidney and lungs was also detected in the sepsis group treated with simvastatinin comparison to the other groups.

CONCLUSIONS: Statin treatment altered the biodistribution of Tc-99m-sestamibi with increased cardiac and solid organ activity in rats with abdominal sepsis, while no impact on controls. Increased myocardial tracer activity may be a result of a possible protection effect due to increased tissue perfusion mediated by statins.

Key words: Simvastatin. Sepsis. Inflammation. Heart. Technetium Tc 99m Sestamibi. Rats. 


\section{Introduction}

Sepsis is the leading cause of death in critically ill patients $^{1}$, mainly as a result of multiple organ failure. Cardiac dysfunction is one of the complications of sepsis, being capable of increasing the mortality by $70 \%{ }^{2}$.

The mechanisms of sepsis-induced cardiac dysfunction have been studied extensively ${ }^{3}$. In recent years, several drugs have been tested for prevention and treatment of sepsis, with discouraging results. Some studies, however, are showing benefits with HMG-CoA reductase inhibitor (enzyme responsible for the biosynthesis of cholesterol). Currently it is consolidated that statins (HMG-CoA reductase inhibitors), reduce mortality in patients with atherosclerosis ${ }^{4}$, reduce the volume of atherosclerotic plaque inflammation and control mechanisms associated with the atheroma genesis ${ }^{5}$. Other effects of statins that are increasingly being reported are the imunomodulation effects ${ }^{6}$. It has been also been established that statins can increase the expression of nitric oxide $(\mathrm{NO})^{7}$.

In sepsis induced cardiac dysfunction, a protective role for statins has been suggested. Using a circulatory shock model induced by lipopolysaccharide (LPS) in guinea pigs, Giuoti-Paiva et $a l .{ }^{8}$ evaluated the production of $\mathrm{NO}$ and the cardiovascular response to the infusion of phenylephrine in simvastatin treated or non-treated groups. NO levels increased significantly two hours after the injection of LPS compared to the control group. In the group pre-treated with simvastatin the NO levels were significantly reduced. LPS injection produced prolonged hypotension in the experimental group; pretreatment with simvastatin did not prevent this hypotensive effect, but the response to phenylephrine was restored in the statin treated group.

Another factor responsible for septic cardiac dysfunction is the poor distribution of regional blood flow induced by sepsis. Poor blood flow distribution can contribute to myocardial dysfunction, generating areas of ischemia. It is assumed that statins also have vasoprotective effects. In a study by Liuba et al. ${ }^{9}$, coronary flow was measured in pigs with acute respiratory infection after treatment with simvastatin. Animals with infection who have not received prior treatment with simvastatin had significant decrease in coronary flow velocity, indicating vasoconstriction.

${ }^{99 \mathrm{~m}} \mathrm{Tc}$-sestamibi is a radiopharmaceutical that is widely used for myocardial perfusion imaging. The kinetics of this radiopharmaceutical in the myocardium and its biodistribution has been reported in several experimental models ${ }^{10,11}$. In the presence of irreversible myocardial injury, mitochondrial membranes are depolarized by changing the uptake of ${ }^{99 \mathrm{~m}} \mathrm{Tc}$-sestamibi ${ }^{12}$. The uptake of ${ }^{99 \mathrm{~m}} \mathrm{Tc}$-sestamibi is dependent on the myocardial tissue viability and regional blood flow ${ }^{13}$

Assuming that cardiac dysfunction can be caused or aggravated by sepsis, and that the inhibition of inflammation is one of many pleiotropic effects of statins, we tested the following hypothesis: pretreatment with simvastatin have a protection effect on the heart, and can possibly have an impact on the cardiac uptake and biodistribution of ${ }^{99 \mathrm{~m}} \mathrm{Tc}$-sestamibi using an experimental model of abdominal sepsis in rats.

\section{Methods}

Twenty-four Wistar rats (four months old, weighing 260 $\pm 28 \mathrm{~g}$ ) supplied by the Nucleus of Experimental Surgery, Federal University of Rio Grande do Norte, were randomly distributed into four groups ( $\mathrm{n}=6$ per group): 1) sepsis with simvastatin treatment, 2) sepsis with vehicle, 3) sham control with simvastatin and 4) sham control with vehicle. They were kept in individual cages with water and standard rodent chow (Presence ${ }^{\circledR}$ ) ad libitum, previously passing through a period of seven days acclimation on the laboratory. They were kept in a controlled temperature $\left(22^{\circ} \mathrm{C}\right)$, with cycles of $12 \mathrm{~h}$ light-dark and handled in accordance with the Law 11.794, Brazil.

\section{Sepsis induction}

Animals were fasted $12 \mathrm{~h}$ before the experiment and anesthetized with intramuscular injection of $0.1 \mathrm{~mL} / 100 \mathrm{~g}$ weight, of a solution prepared with $1.0 \mathrm{~mL}$ of ketamine $(50 \mathrm{mg} / \mathrm{mL})$ and $1.0 \mathrm{~mL}$ of xilazine $(20 \mathrm{mg} / \mathrm{mL})$. They breathed spontaneously throughout the procedures. After shaving, the abdominal skin was disinfected with $70 \%$ alcohol. All procedures were performed under sterile conditions. A $3 \mathrm{~cm}$ midline laparotomy was performed and cecal ligation and puncture (CLP) was performed. The cecum was exposed, ligated with cotton $3-0$, one cm distally to the ileocecal valve to avoid intestinal obstruction. Four punctures were performed with a 22-gauge needle, squeezed gently to force out a small amount of feces, and then it was returned to the abdominal cavity. The abdominal incision was closed with 4-0 nylon sutures. Midline laparotomy $(3 \mathrm{~cm})$ and gentle manipulation of cecum was performed in the sham rats. Pain medication (meperidine $10 \mathrm{mg} /$ body weight) and volume support ( $\mathrm{NaCl} 0.9 \%, 0.05 \mathrm{~mL} / \mathrm{g}$ body weight) were applied subcutaneously immediately after the induction of sepsis and every 12 hours thereafter.

Twelve animals were treated orally with simvastatin and twelve with $0.9 \%$ saline. Six animals with sepsis and six sham were injected daily with oral suspension of simvastatin $10 \mathrm{mg} / \mathrm{kg} /$ 
day, (gavage) for three days prior to induction of peritonitis and $2 \mathrm{~h}$ before the CLP. The other rats received oral $1 \mathrm{ml}$ of $0.9 \%$ saline.

After 24 hours postoperative observation the animals were anesthetized, and a dose of $1.0 \mathrm{MBq}$ of ${ }^{99 \mathrm{~m}} \mathrm{Tc}$-sestamibi was injected intravenously. The injected dose (ID) was calculated as the difference between the measured radioactivity in the seringe before and after injection, using a curiemeter (Capintec CRC-25R). Thirty minutes after injection, animals were euthanized, and the heart, lung, kidney and liver were resected. The samples were quickly washed in saline, weighed on a precision balance (Mark $160^{\circledR}$, Bel equipment, Italy) and then introduced into test tubes for the determination of biodistribution of ${ }^{99 \mathrm{~m}} \mathrm{Tc}$-sestamibi in an automatic gamma counter (Wizard $1470^{\circledR}$, Perkin-Elmer, Finland). The decay corrected activity in counts per minute (CPM) in the tissues of interest was calculated as a percentage of the injected dose per gram of tissue $(\% \mathrm{ID} / \mathrm{g})$.

After obtaining the tissue biodistribution measurements, the fresh hearts were cut and washed in running water to enable rapid and uniform action of the fixative solution. Then the samples were fixed in $10 \%$ buffered formalin for 48 hours and processed for 18 hours in an automatic tissue processor, using Leica equipment TP 1020, German. Prior to embedding in paraffin, the left ventricles of fixed hearts were cut with punch (6 $\mathrm{mm}$ diameter), for standardization of samples. Histological sections were obtained with microtome Leica RM 2125 RTS, 03 microns thick. The fixed specimens were stained with hematoxylin/eosin for morphological analysis by optical microscopy, using the CX41 microscope (Olympus, Tokyo, Japan). Sections were examined in high magnification power fields (x400) to determine the presence of adherent and infiltrating neutrophils, eosinophils, basophils, monocytes, lymphocytes and platelets. The total number of cells was analyzed in six fields for each heart expressed in cells per square millimeter. The quantitative analysis was performed using a video-assisted software (Image ProPlus 6.0, Media Cyber).

\section{Data analysis}

All data were presented as mean \pm standard deviation and compared by ANOVA and Tukey test. The difference between the means was considered statistically significant when $\mathrm{p}<0.05$.

\section{Results}

All animals survived the experiments. Contraction necrosis or interstitial fibrosis was not seen in any of the evaluated hearts. Interstitial edema, mononuclear infiltrate, myocytolysis and tissue hemorrhage were found, but no differences were detected when comparing sepsis and sham groups, with and without treatment with simvastatin.

The average time for resection of organs for weighing on a precision scale and measurements of the ${ }^{99 \mathrm{~m}} \mathrm{Tc}$-sestamibi activities was 10 minutes per animal. Table 1 show the percentage of the injected activity per gram of tissue $(\% \mathrm{ID} / \mathrm{g})$ detected in the heart, lung, kidney and liver, in each group.

The highest \%ID of ${ }^{99 \mathrm{~m}} \mathrm{Tc}-$-sestamibi per gram of tissue was detected in the heart and kidney both in sham and in the sepsis groups (Table 1). The lowest \%ID of ${ }^{99 \mathrm{~m}} \mathrm{Tc}$-sestamibi per gram of tissue was detected in the lungs in all groups (Table 1).

There were no significant differences in the $\% \mathrm{ID} / \mathrm{g}{ }^{99 \mathrm{~m}} \mathrm{Tc}-$ sestamibi of per gram of tissue in the heart, liver, kidney and lung among sham groups treated with simvastatin and those treated with saline (Table 1 ). The $\% \mathrm{ID} / \mathrm{g}$ of the liver and the kidney was significantly higher in the sepsis groups, when compared with the sham groups (Table 1 ). The $\% \mathrm{ID} / \mathrm{g}$ in the heart and lung was lower in the sepsis group treated with saline when compared to sham, however with no significant difference (Table 1 ). The $\% \mathrm{ID} / \mathrm{g}$ of the heart was significantly higher in the sepsis group pretreated with simvastatin than in the sepsis group treated with saline. The myocardium activity was also significantly higher than in sham groups treated with simvastatin and with saline. There was also a significant $\% \mathrm{ID} / \mathrm{g}$ of tissue in the lung, kidney and liver in sepsis groups treated with simvastatin, when compared with the control groups, and when compared to the sepsis group treated with saline (Table 1).

TABLE 1 - Percentage of injected dose of ${ }^{99 m}$ Tc-sestamibi per gram of tissue $(\% \mathrm{ID} / \mathrm{g})$ in each group.

\begin{tabular}{|c|c|c|c|c|c|}
\hline \multirow{2}{*}{ Organs } & \multicolumn{4}{|c|}{$\%$ ID/g per group } & \multirow{2}{*}{$\mathrm{p}$-value ${ }^{(1}$} \\
\hline & Sham simvastatin & Sham Saline & Sepsis simvastatin & Sepsis Saline & \\
\hline Heart $^{2}$ & $1.19 \pm 0.33^{*}$ & $1.28 \pm 0.22^{¥}$ & $1.86 \pm 0.26^{* ¥ \dagger}$ & $1.04 \pm 0.21^{\dagger}$ & $<0.001$ \\
\hline Kidney $^{2}$ & $1.38 \pm 0.35^{*}$ & $1.94 \pm 0.70^{¥}$ & $4.99 \pm 0.82^{* ¥}$ & $3.31 \pm 1.71^{*}$ & $<0.001$ \\
\hline Lung $^{2}$ & $0.26 \pm 0.14^{*}$ & $0.26 \pm 0.06^{¥}$ & $0.54 \pm 0.06^{* ¥ \dagger}$ & $0.18 \pm 0.08^{\dagger}$ & $<0.001$ \\
\hline
\end{tabular}

Mean \pm standard deviation

1 - $p$ value from ANOVA.

2 - The values followed by equal symbols are significantly different by Tukey multiple comparisons test, at a significance level of 5\%. 


\section{Discussion}

Recently, our group showed that simvastatin had significant anti-inflammatory effect in rats with abdominal sepsis, using the CLP model. The results showed that TNF- $\alpha$, IL- $1 \beta$ and IL-6 values in septic group previously treated with simvastatin were significantly lower than in the untreated sepsis group. The same occurred in total leukocytes and neutrophils ${ }^{14}$. In another study, our group showed that simvastatin also had important anti-inflammatory action in the abdominal sepsis in diabetic rats. Simvastatin reduced mortality in diabetic rats. Serum levels of TNF- $\alpha$, IL-1 $\beta$, IL-6, C-reactive protein, procalcitonin, leukocytes, and neutrophils were significantly lower in diabetic and nondiabetic rats with sepsis treated with simvastatin, than in the group treated with saline ${ }^{15}$. In this study, cardiac and systemic effects of simvastatin pretreatment were analyzed in septic rats, using ${ }^{99 \mathrm{~m}} \mathrm{Tc}$ sestamibi as a specific substrate to assess biodistribution in the heart, liver, kidney and lung.

The exact mechanism of cellular uptake of ${ }^{99 \mathrm{~m}} \mathrm{Tc}$-sestamibi is still unclear. Due to the lipophilic nature of the ${ }^{99 \mathrm{~m} T c}$-sestamibi cation, it is apparently distributed across biological membranes in response to transmembrane potential ${ }^{12}$. Uptake likely occurs passively through the plasma and mitochondrial membranes, with ${ }^{99 \mathrm{~m}} \mathrm{Tc}$-sestamibi being retained by the mitochondria due to the large negative membrane potential. Tissues that have high concentration of mitochondria, such as the heart, retains a high proportion of ${ }^{99 m} \mathrm{Tc}$-sestamibi ${ }^{16}$. This radiopharmaceutical is distributed in the myocardium in proportion to the coronary blood flow ${ }^{11}$.

Despite the effect of electrical potential and passive diffusion on ${ }^{99 \mathrm{~m}} \mathrm{Tc}$-sestamibi cellular distribution, there are also transporters responsible for tracer efflux and cellular excretion. Some studies have demonstrated that during inflammation, the expression of several carriers is modified in rodents. Previous studies have described downregulation of the expression of mRNA mdr1a, mdr1b, MRP2 and SPGP as well as lower activity of liver P-glycoprotein ${ }^{17}$. It has been stated that the release of proinflammatory cytokines, including TNF- $\alpha$, IL- $1 \beta$ and IL-6 during the inflammatory response is primarily involved in mediating the downregulation ${ }^{18}$.

Overall, the results of our study showed that CLPinduced abdominal sepsis was associated with increased retention of ${ }^{99 \mathrm{~m}} \mathrm{Tc}$-sestamibi in the heart and in the liver, kidney and lung samples, especially in sepsis group pretreated with simvastatin. Wang et al. ${ }^{19}$ showed similar results evaluating the activity of P-glycoprotein through the biodistribution of $99 \mathrm{~m} \mathrm{Tc}$-sestamibi in endotoxemic rats. These findings could possibly reflect low excretion and distribution of ${ }^{99 \mathrm{~m}} \mathrm{Tc}$-sestamibi, secondary the lower activity of P-glycoprotein during sepsis. The ${ }^{99 \mathrm{~m}} \mathrm{Tc}-$ sestamibi is eliminated from the body primarily through active secretion mediated by the activity of P-glycoprotein. As such, high levels of ${ }^{99 m} \mathrm{Tc}$-sestamibi in the blood of animals treated with LPS possibly reflect altered biodistribution and depressed tracer clearance secondary to downregulation of the expression of P-glycoprotein in the presence of inflammation. There may be increased trapping of solid organ ${ }^{99 \mathrm{~m}} \mathrm{Tc}$-sestamibi partly attributed to increased blood concentration.

A multicenter trial recently evaluated the use of rosuvastatin in patients with sepsis associated with adult respiratory distress ${ }^{20}$. The results showed that the rosuvastatin did not improve clinical response and may have contributed to increased hepatic and renal dysfunction. If statins are actually associated with more hepatic and renal dysfunction in sepsis, this may partially explain the results obtained in our study. We showed altered solid organ tracer biodistribution in cardiac, hepatic, renal and lung tissues in rats treated with simvastatin. This increased dose distribution of ${ }^{99 \mathrm{~m}} \mathrm{Tc}$-sestamibi may be secondary to increased blood concentration of ${ }^{99 \mathrm{~m}}$ Tc-sestamibi. However, Wang et al. ${ }^{19}$ also showed that changes in blood concentration could not fully explain changes in accumulation in vital organs.

Importantly, no significant correlation between serum levels of ${ }^{99 \mathrm{~m}} \mathrm{Tc}$-sestamibi and accumulation were found in organs both in the group treated with LPS and control groups. It is therefore less likely that there is statin-induced liver and kidney dysfunction leading to increased $99 \mathrm{mTc}$-sestamibi cardiac retention in the sepsis group with simvastatin. Also, different from Wang et al. ${ }^{19}$, our results showed that the whole heart distribution of $99 \mathrm{mTc}-$ sestamibi in sepsis pretreated with simvastatin was significantly higher than in the saline treated and sham groups. The mechanism for the increased cardiac distribution of $99 \mathrm{mTc}$-sestamibi is unclear. One possible hypothesis is that simvastain could possibly be enhancing the intracellular accumulation of $99 \mathrm{mTc}$-sestamibi due to presumable amplification of P-glycoprotein function inhibition. Mendes et al. ${ }^{21}$ showed for example that cyclosporin A, an MDR modulator, modified the 99mTc-sestamibi biodistribution by inhibiting the P-glycoprotein function. Therefore, simvastatin in the presence of systemic inflammation during sepsis could possibly have similar effect modifying the P-glycoprotein function, besides the sepsis induced inflammatory effects.

Previous studies have demonstrated that P-glycoprotein and mdr1 mRNA are expressed in the endothelium of arterioles and capillaries of the heart ${ }^{22}$. Wang et al. ${ }^{19}$ detected mdrla mRNA in heart, but at lower levels than those in the liver and kidney. 
However, mdrla levels were significantly depressed in the heart of LPS-treated mice, but this decrease caused only slight changes in the cardiac biodistribution of ${ }^{99 \mathrm{~m}} \mathrm{Tc}$-sestamibi. High affinity of heart tissue by ${ }^{99 \mathrm{~m}} \mathrm{Tc}$-sestamibi and the relative low activity of P-glycoprotein may have contributed to these findings. Therefore, changes in P-glycoprotein activity induced by inflammation are unlikely to cause significant impact of cardiac uptake of ${ }^{99 \mathrm{~m}} \mathrm{Tc}$ sestamibi. This finding is consistent with the findings of our study. Our results showed no significant changes in the levels of ${ }^{99 \mathrm{~m}} \mathrm{Tc}-$ sestamibi in sepsis group treated with saline compared to the sham group. However, the whole heart distribution of ${ }^{99 \mathrm{~m}} \mathrm{Tc}$-sestamibi in sepsis rats pretreated with simvastatin was significantly higher than in the saline treated and sham groups.

Another hypothesis to explain the increased cardiac biodistribution of ${ }^{99 \mathrm{~m}} \mathrm{Tc}$-sestamibi in the sepsis group previously treated with simvastatin is possibly due to increased tissue perfusion secondary to coronary vasodilation induced by increasing concentration of nitric oxide under the action of statins ${ }^{7}$. Merx et $a l .{ }^{23}$ showed an improved survival of rats with sepsis, justifying that this was due to cardiac and hemodynamic stability after treatment with statins. Their study also showed that the cardiac and hemodynamic stability was associated not only to sinvastatin, but with other statins as weel. The mechanisms were related to the better susceptibility to stimulation of nitric oxide synthase and reduction of leukocyte endothelial adhesion in animals treated with statins. To better assess this hypothesis experiments with microspheres labeled with raioactive isotopes or quantitative myocardium perfusion PET kinetic studies using ammonia N-13 or labeled water O-15 would be necessary. Therefore, a proven statin protection effect could have a major impact in sepsis induced cardiac dysfunction treatment.

\section{Conclusions}

Statin treatment altered the biodistribution of Tc-99msestamibi with increased cardiac and solid organ activity in rats with abdominal sepsis, while no impact on controls. Increased myocardial tracer activity may be a result of a possible protection effect due to increased tissue perfusion mediated by statins.

\section{References}

1. Hotchkiss RS, Karl IE. The pathophysiology and treatment of sepsis. New Eng J Med. 2003 Jan 9;348(2):138-50. PMID: 12519925.

2. Blanco J, Muriel-Bombín A, Sagredo V, Taboada F, Gandía F, Tamayo L, Collado J, García-Labattut A, Carriedo D, Valledor M, De Frutos M, López MJ, Caballero A, Guerra J, Alvarez B, Mayo A, Villar J. Incidence, organ dysfunction and mortality in severe sepsis: a Spanish multicentre study. Crit Care. 2008;12(6):R158-60. PMID: 19091069.3. Tavener SA, Kubes P. Cellular and molecular mechanisms underlying LPS-associated myocyte impairment. Am J Physiol Heart Circ Physiol. 2006 Feb;290(2):H800-6. PMID: 16172157.

4. LaRosa JC, Grundy SM, Waters DD, Shear C, Barter P, Fruchart JC, Gotto AM, Greten H, Kastelein JJ, Shepherd J, Wenger NK. Intensive lipid lowering with atorvastatin in patients with stable coronary disease. New Eng J Med. 2005 Apr 7;352(14):1425-35. PMID: 15755765.

5. Libby P, Ridker PM, Maseri A. Inflammation and atherosclerosis. Circulation. 2002 Mar 5;105(9):1135-43. PMID: 11877368.

6. Mach F. Toward a role for statins in immunomodulation. Mol Interv. 2002 Dec;2(8):478-80. PMID: 14993398.

7. Laufs U, La Fata V, Plutzky J, Liao JK. Upregulation of endothelial nitric oxide synthase by HMG CoA reductase inhibitors. Circulation. 1998 Mar 31;97(12):1129-35. PMID: 9537338.

8. Giusti-Paiva A, Martinez MR, Felix JV, da Rocha MJ, Carnio EC, Elias LL, Antunes-Rodrigues J. Simvastatin decreases nitric oxide overproduction and reverts the impaired vascular responsiveness induced by endotoxic shock in rats. Shock. 2004 Mar;21(3):271-5. PMID: 14770041.

9. Liuba P, Pesonen E, Forslid A, Paakkari I, Kornerup-Hansen A, Kovanen P, Pentikäinen M, Persson K, Østergård G. Protective effects of simvastatin on coronary artery function in swine with acute infection. Atherosclerosis. 2006 Jun;186(2):331-6. PMID: 16223501.

10. Dahlberg ST, Leppo JA. Myocardial kinetics of radiolabeled perfusion agents: basis for perfusion imaging. J Nucl Cardiol. 1994 Mar-Apr;1(2 Pt 1):189-97. PMID: 9420686.

11. Beller GA, Sinusas AJ. Experimental studies of the physiologic properties of technetium-99m isonitriles. Am J Cardiol. 1990 Oct 16;66(13):5E-8E. PMID: 2145747.

12. Piwnica-Worms D, Kronauge JF, Chiu ML. Uptake and retention of hexakis (2-methoxyisobutyl isonitrile) technetium(I) in cultured chick myocardial cells. Mitochondrial and plasma membrane potential dependence. Circulation. 1990 Nov;82(5):1826-38. PMID: 2225379

13. Beller GA, Glover DK, Edwards NC, Ruiz M, Simanis JP, Watson DD. $99 \mathrm{mTc}$-sestamibi uptake and retention during myocardial ischemia and reperfusion. Circulation. 1993 Jun;87(6):2033-42. PMID: 8504518.

14. Souza Neto JL, Araujo Filho I, Rego AC, Dominici VA, Azevedo IM, Egito ES, Brandão-Neto J, Medeiros AC. Effects of simvastatin in abdominal sepsis in rats. Acta Cir Bras. 2006;21 Suppl 4:8-12. PMID: 17293958.

15. Araujo-Filho I, Jacome DT, Rego AC, Azevedo IM, Egito ES, Medeiros AC. Effect of the simvastatin in abdominal sepsis of diabetic rats. Rev Col Bras Cir. 2010 Feb;37(1):39-44. PMID: 20414574.

16. Maffioli L, Gasparini M, Chiti A, Gramaglia A, Mongioj V, Pozzi A, Bombardieri E. Clinical role of technetium-99m sestamibi singlephoton emission tomography in evaluating pretreated patients with brain tumours. Eur J Nucl Med. 1996 Mar;23(3):308-11. PMID: 8599962.

17. Piquette-Miller M, Pak A, Kim H, Anari R, Shahzamani A. Decreased expression and activity of P-glycoprotein in rat liver during acute inflammation. Pharm Res. 1998 May;15(5):706-11. PMID: 9619778.

18. Hartmann G, Kim H, Piquette-Miller M. Regulation of the hepatic multidrug resistance gene expression by endotoxin and inflammatory cytokines in mice. Int Immunopharm. 2001 Feb;1(2):189-99. PMID: 11360920.

19. Wang JH, Scollard DA, Teng S, Reilly RM, Piquette-Miller M. Detection of P-glycoprotein activity in endotoxemic rats by $99 \mathrm{mTc}-$ 
Heart and systemic effects of statin pretreatment in a rat model of abdominal sepsis. Assessment by Tc ${ }^{99 m}$-sestamibi biodistribition

sestamibi imaging. J Nucl Med. 2005 Sep;46(9):1537-45. PMID: 16157538

20. National Heart L, Blood Institute ACTN, Truwit JD, Bernard GR, Steingrub J, Matthay MA, Liu KD, Albertson TE, Brower RG, Shanholtz C, Rock P, Douglas IS, deBoisblanc BP, Hough CL, Hite RD, Thompson BT. Rosuvastatin for sepsis-associated acute respiratory distress syndrome. New Eng J Med. 2014 Jun 5;370(23):2191-200. PMID: 24835849.

21. Mendes F, Gano L, Fernandes C, Paulo A, Santos I. Studies of the myocardial uptake and excretion mechanisms of a novel $99 \mathrm{mTc}$ heart perfusion agent. Nucl Med Biol. 2012 Feb;39(2):207-13. PMID: 22079035.

22. Meissner K, Sperker B, Karsten C, Meyer Zu Schwabedissen H, Seeland U, Bohm M, Bien S, Dazert P, Kunert-Keil C, Vogelgesang S, Warzok R, Siegmund W, Cascorbi I, Wendt M, Kroemer HK. Expression and localization of P-glycoprotein in human heart: effects of cardiomyopathy. J Histochem Cytochem. 2002 Oct;50(10):13516. PMID: 12364568.

23. Merx MW, Liehn EA, Graf J, van de Sandt A, Schaltenbrand M, Schrader J, Hanrath P, Weber C. Statin treatment after onset of sepsis in a murine model improves survival. Circulation. $2005 \mathrm{Jul}$ 5;112(1):117-24. PMID: 15998696.

\section{Correspondence:}

Robson de Macedo Filho

Núcleo de Cirurgia Experimental

Av. Nilo Peçanha, 620

59012-300 Natal - RN Brasil

robmacedo@yahoo.com

Received: Feb 12, 2015

Review: Apr 14, 2015

Accepted: May 13, 2015

Financial source: National Council for Scientific and Technological Development (CNPq-Grant 478600/2011-9)

${ }^{1}$ Research performed at Nucleus of Experimental Surgery, Department of Surgery, Federal University of Rio Grande do Norte (UFRN), Brazil. Part of PhD degree thesis, Postgraduate Program in Health Sciences. Tutor: Aldo Cunha Medeiros. 